\title{
DEATH DURING INDIGENOUS TREATMENTS: CHOCKING DUE TO A HALF OF A LIME
}

\author{
Senanayake S.M.H.M.K.
}

Consultant Judicial Medical Officer, Teaching Hospital, Anuradapura, Sri Lanka

\begin{abstract}
Thirty six years old woman, who was suffering from convulsions, decided to follow indigenous treatments. After beating with a coconut flower, when a lime was cut over the mouth, indigenous practitioner asked the patient to swallow the cut lime, put the cut pieces into the mouth and pushed them deep using the cutting instrument. She struggled and found dead. Multiple injuries were found. Larynx was obstructed with half of a lime. This case shows that a conscious adult also may die due to choking if a food particle is forcefully pushed deep into the mouth. It is an example for homicidal chocking. Health education and regulations are necessary on indigenous treatments.
\end{abstract}

Key words: indigenous treatment, choking, lime

Corresponding author:

dilruksena62@yahoo.co.uk

\section{INTRODUCTION}

Fatal obstruction of the internal airway (chocking) can occur between the pharynx and bifurcation of trachea. Food that can fill the pharynx, (such as bananas, marshmallows, or gelatinous candies) can be a danger for persons of any age ${ }^{1}$, but commonly children ${ }^{2}$ Choking due to a foreign object resulted in 140,000 deaths in 1990 , which has increased to 162,000 deaths in 2013. ${ }^{3}$ Blood and dentures had also caused death due to choking. When adults die due to chocking, usually there is a contributory factor, such as alcohol or drug abuse and medicinal drugs such as tranquilizers in psychiatric patients.

\section{CASE REPORT}

Thirty six years old mother of one child was suffering from convulsions during last 10 years. She was under the treatments for epilepsy. To obtain a cure, she and her husband decided to follow indigenous treatments. One night, indigenous treatment started with a dance for the devil, followed by beating with a coconut flower, burning of feet, anal and genital area with a torch, and cutting of limes over various body parts. When a lime was cut over the mouth, indigenous practitioner instructed the patient to swallow the cut lime and put the pieces of lime into the mouth and pushed the pieces down the throat with the cutting instrument. She struggled and became motionless. When she was brought to the hospital she was found to be dead.

\section{Post mortem examination showed the following findings}

- Multiple small abrasions around the mouth, hands and chest.

- Patterned contusions compatible with coconut flower on the left loin.

- Contusions on the back and both loins.

- Black discoloration and blisters of skin around anus and feet.

- Burnt pubic hair.

- Fresh dislocations of lower central incisors teeth.

- Half of a lime obstructing the pharynx. 


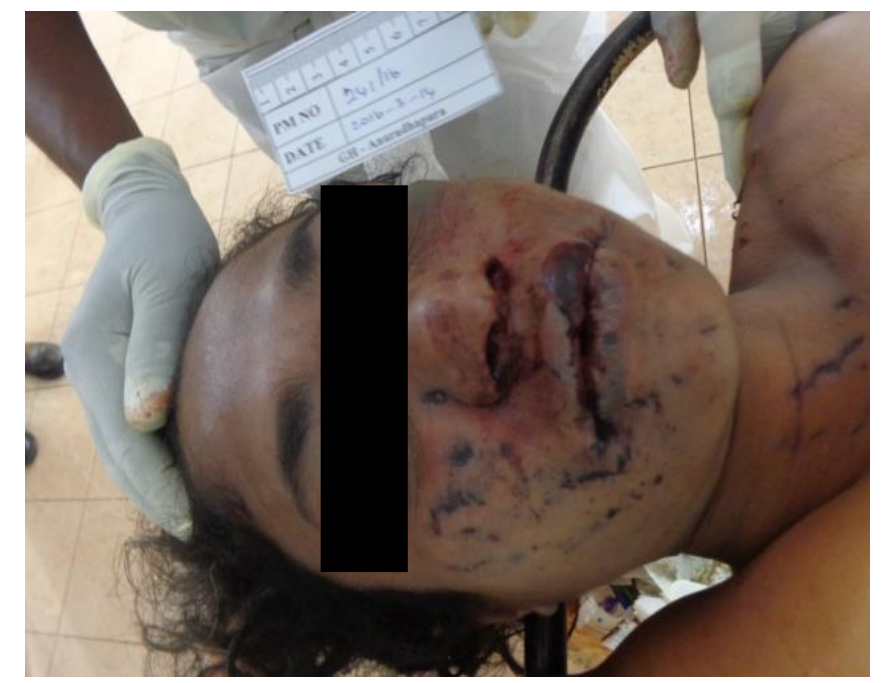

Photo 01 : Patterned contusion of the face and lip contusions

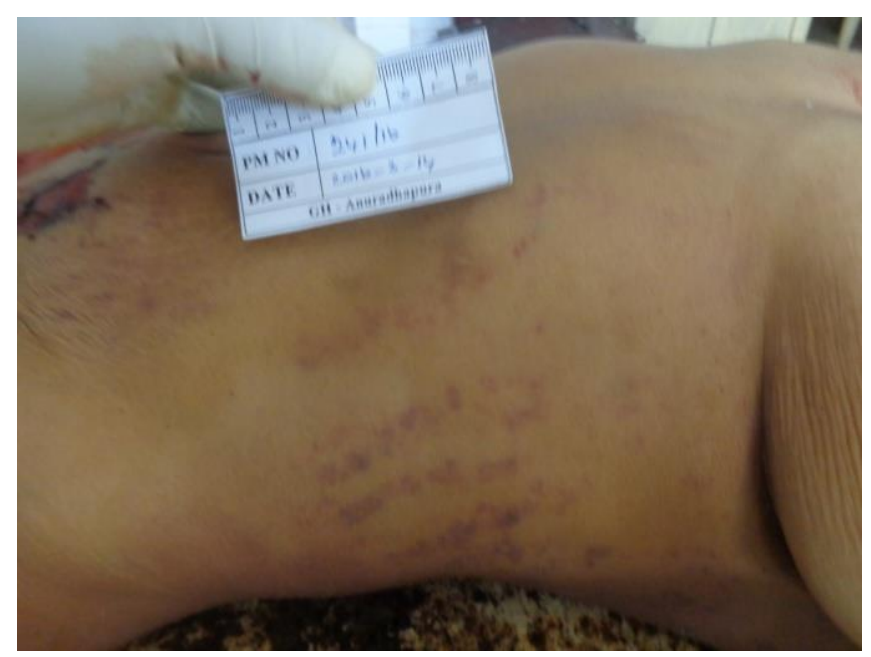

Photo 03: Patterned contusion by coconut flower on the left loin.

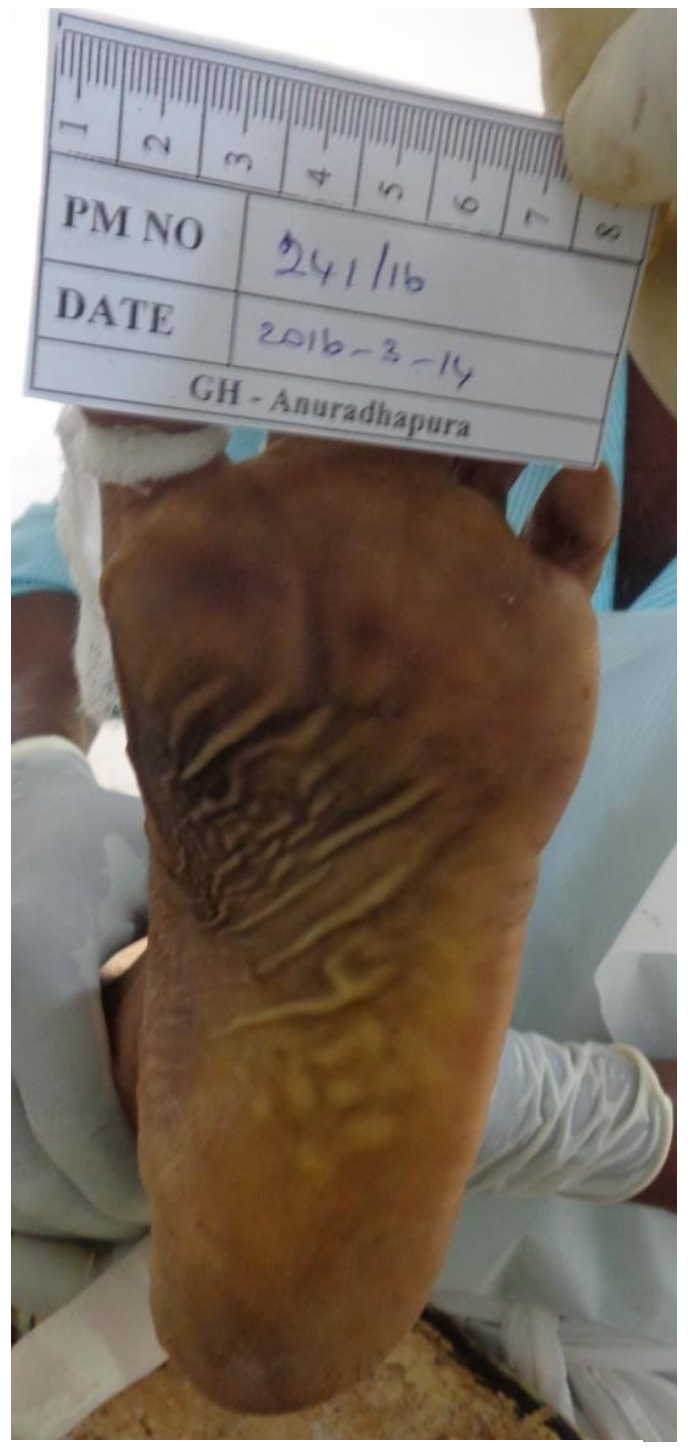

Photo 02: Burn on sole

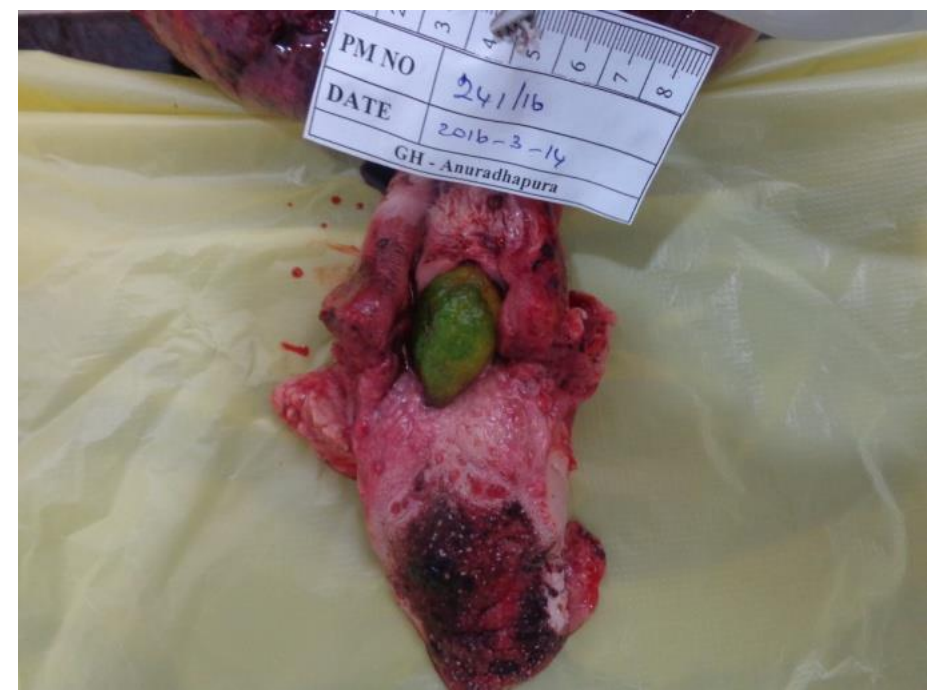

Photo 04: Half of the lime in the pharynx 
History provided by the husband suggested choking as the most possible cause of death. Postmortem examination revealed obstruction of the larynx with a half of a lime. Injuries were superficial and were not sufficient to cause death. There was no evidence of blood aspiration even though dislocated teeth were found. No postmortem changes of sudden natural death were found. Cause of the death was pronounced as;

1a- Asphyxia

1b- Chocking with a half of a lime

\section{DISCUSSION}

This is a rare form of fatal chocking because the adult female had died due to forced insertion of a half of a lime down the throat when there is no factor for incapacitation. Forced insertion into the mouth by the cutting instrument had been witnessed by the husband and the injury pattern around mouth confirms the history.

Mechanisms of death in choking are hypoxia and neurogenic cardiac arrest. ${ }^{4}$ Hypoxia will produce postmortem features of asphyxia and neurogenic cardiac arrest will produce none. In this case, asphyxia features were not evident: therefore, the fatal mechanism is neurogenic cardiac arrest. When there is a doubt about the origin of the place of the food particle, whether from mouth or stomach, a lithmus test is usually done. If the test shows acidic reaction, it indicates that the food particle had originated from the stomach. In this case, such a test is not valid, because the food particle was a half of a lime. ${ }^{5}$

A visit to the scene and history from eye witnesses and relations will help to find the circumstances of the fatal event. Usual history is that after aspiration of the foreignbody, victims show symptoms of forceful cough, clutching of throat or chest, and then collapse. In this case, the victim had struggled and became motion-less. Manner of death in choking is usually accidental. It is rare, when a food particle is pushed down deep into the mouth, as in this case, the event goes beyond a simple accident. With the knowledge and intention of the perpetrator, it could be an accident, medical negligence or homicide.

\section{CONCLUSION}

A conscious adult can also die due to choking if a food particle is forcefully pushed into the mouth. Health education and regulations are necessary for indigenous treatments.

\section{REFERENCES}

1. Roya S. Swallow Safely: How Swallowing Problems Threaten the Elderly and Others. 2010.1st ed. Natick, USA: Inside/Outside Press. pp. 46-47.

2. Gregori D et al. Foreign bodies in the upper airways: the experience of two Italian hospitals. Journal of preventive medicine and hygiene. $2007 ; 48(1): 24-6$.

3. GBD 2013 Mortality and Causes of Death, Collaborators. Global, regional, and national age-sex specific all-cause and cause-specific mortality for 240 causes of death, 19902013: a systematic analysis for the Global Burden of Disease Study 2013. Lancet. 2015;385: 117-71.

4. Saukko P, Knight B. Knight's Forensic Pathology. Philadelphia. CRC press.4th edi.2016; 362-364

5. Spitz WU. Asphyxia. In: Spitz WU editor. Spitz and fisher's Medicolegal Investigation of Death. Illinos; Charles C Thomas, $4^{\text {th }}$ di. $2004 ; 824$ 